\title{
Numerical Study of Wave Forces on Crown Walls of Mound Breakwaters with Parapets
}

\author{
Jorge Molines ${ }^{1, *(\mathbb{D}}$, Arnau Bayón ${ }^{2} \mathbb{C}$, M. Esther Gómez-Martín ${ }^{1}\left[\right.$ and Josep R. Medina $^{1}(\mathbb{C}$ \\ 1 Department of Transportation, Universitat Politècnica de València, Camino de Vera s/n, \\ 46022 Valencia, Spain; mgomar00@upv.es (M.E.G.-M.); jrmedina@upv.es (J.R.M.) \\ 2 Department of Hydraulic Engineering and Environment, Universitat Politècnica de València, \\ Camino de Vera s/n, 46022 Valencia, Spain; arbabar@upv.es \\ * Correspondence: jormollo@upv.es
}

Received: 25 February 2020; Accepted: 9 April 2020; Published: 11 April 2020

\begin{abstract}
The influence of parapets on crown walls of mound breakwaters on wave forces has not been extensively analyzed in the literature. In this study, numerical experiments were carried out using the open-source platform OpenFOAM ${ }^{\circledR}$ to evaluate the influence of nine crown wall geometries with and without parapets. The OpenFOAM ${ }^{\circledR}$ model was validated with laboratory experiments. Dimensionless horizontal forces and overturning moments due to horizontal forces increase when there is a parapet. Dimensionless up-lift forces provide similar results, regardless of the existence of a parapet. Crown walls with parapets increase the horizontal wave forces and overturning moments due to horizontal wave forces by a factor of two.
\end{abstract}

Keywords: wave forces; wave overtopping; bullnose; parapet; recurved wall; mound breakwater; CFD; VOF; OpenFOAM ${ }^{\circledR}$; crown wall

\section{Introduction}

The crest level of a mound breakwater is designed to work with lower mean wave overtopping discharges than tolerable limits for port operation and structural safety. A monolithic concrete wall is usually constructed on top of the breakwater to increase the crest freeboard, improve accessibility, and provide support for facilities. In order to reduce the wave overtopping on existing or new mound breakwaters with a crown wall, a parapet can be constructed on the crown wall to return part of the flow to the sea. Molines et al. [1] studied the influence of a parapet on wave overtopping of mound breakwaters with crown walls. The authors noticed a reduction in the dimensionless mean wave overtopping discharges when a parapet was constructed. Molines et al. [1] analyzed the effects of the parapet angle $\left(\varepsilon_{p}\right)$, parapet width $\left(w_{p}\right)$, and parapet height $\left(h_{p}\right)$ on wave overtopping (see Figure 1 ). Low parapet angles $\varepsilon_{p}$ and $w_{p} / h_{p} \approx 1$ provided the largest reduction in the mean wave overtopping rates. The same tests of Molines et al. [1] are used in this study.

Studies on vertical breakwaters with parapets, such as that by Martinelli et al. [2], have concluded that wave forces on the vertical breakwater increased when a parapet was constructed. However, existing methods for evaluating wave forces on crown walls of mound breakwaters by Pedersen [3], Norgaard et al. [4], Molines [5], Molines et al. [6], and Van Gent and van der Werf [7] do not consider the influence of a parapet on the wave forces on crown walls $\left(w_{p}=0\right)$.

In Figure $1, R_{c}$ is the crest freeboard of the structure, $A_{c}$ is the armor crest freeboard of the structure, $F_{c}$ is the crown wall foundation level, $G_{c}$ is the crest width of the structure, $\cot \alpha$ is the armor slope, $h$ is the water depth at the toe, $h_{t}$ is the water depth on the toe berm, $B_{t}$ is the width of the toe berm, $C_{h}$ is the crown wall height, $C_{b}$ is the crown wall width, $h_{p}$ is the parapet height, $w_{p}$ is the parapet width, 
and $\varepsilon_{p}$ is the parapet angle. In this study, the wave characteristics were identified with the significant wave height $\left(H_{m 0}\right)$ and the peak period $\left(T_{p}\right)$.
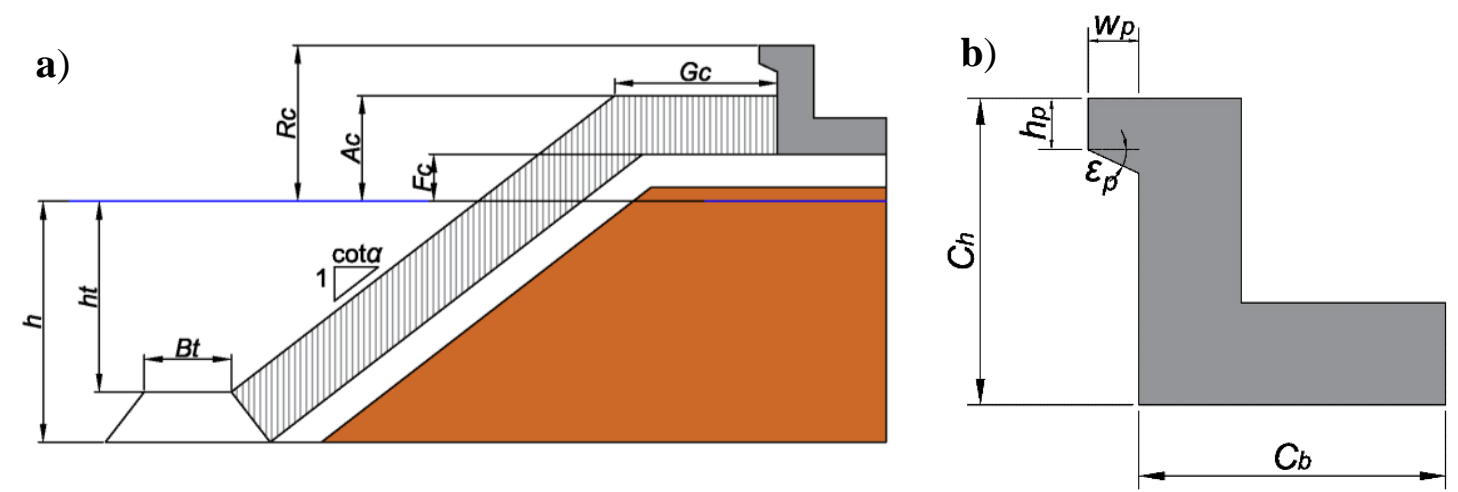

Figure 1. Cross-section of (a) a conventional mound breakwater with a toe berm and crown wall and (b) parapet characteristics.

In this study, the effect of the parapet characteristics on wave forces on crown walls was analyzed based on the numerical tests conducted by Molines et al. [1]. This paper is divided into the following sections. First, the literature on wave forces on coastal structures with parapets is described. Second, 2D physical and numerical model tests are described. Third, the numerical tests are validated. Fourth, the results of wave forces are analyzed, and finally, general conclusions are provided.

\section{Literature Review on Wave Forces on Coastal Structures with Parapets}

Kortenhaus et al. [8,9] analyzed the performance of vertical walls with parapets, focusing on wave overtopping and wave loading. The authors provided a reduction factor defined as


The higher the dimensionless relative crest freeboard $\left(R_{c} / H_{m 0}\right)$, the lower the parameter $k$, with a huge amount of scatter in the data. These authors stated that the parapet provided a small increase in horizontal wave forces when $R_{d} / H_{m 0}>1.5$; however, when $R_{c} / H_{m 0}<1.5$, the horizontal wave forces could increase by between $10 \%$ and $80 \%$.

Pearson et al. [10] reanalyzed the data of Kortenhaus et al. [9] and reported horizontal wave forces on structures with parapets approximately two times higher than those on the vertical wall.

Castellino et al. [11] and Martinelli et al. [2] conducted numerical and physical experiments, respectively, of vertical breakwaters with recurved parapets under non-breaking wave conditions. Their data showed that parapets with an exit angle $\theta=90^{\circ}$ provided impulsive horizontal maximum loads up to five times larger than the loads applied to the vertical wall. The impulsive forces appeared in the range of $0.65 \leq H_{m 0} / R_{c} \leq 0.9$. Parapets with an exit angle $\theta=45^{\circ}$ were not subjected to impulsive loads in the investigated range, and the forces were thus similar to those of the vertical wall case.

Pedersen [3], Norgaard et al. [4], Molines [5], and Van Gent and van der Werf [7] studied the wave loads on crown walls of mound breakwaters without parapets. The authors used the virtual wave run-up as a key variable to estimate the wave forces on the crown wall; the higher the virtual wave run-up, the higher the wave forces on the crown wall. Molines et al. [6] proposed estimating the wave forces on the crown wall of mound breakwaters using the dimensionless mean wave overtopping as the key variable.

\section{Model Tests}

The physical and numerical models used in this study are fully described in Molines et al. [1] and Smolka et al. [12]. In the next sections, a summary of the physical and numerical models focused on the wave forces on crown walls is provided; further details are available in Molines et al. [1]. 


\subsection{Physical Model}

In this study, the two-layer Cubipod armored mound breakwater physical tests were used. A complete description of the tests has been described by Smolka et al. [12]. Tests were carried out in the wind and wave flume of the Laboratory of Ports and Coasts at the Universitat Politècnica de València (LPC-UPV).

Tests were conducted in non-breaking wave conditions. The cross-section tested in the wave flume corresponded to a conventional mound breakwater with a crown wall and without a toe berm. The physical model had $R_{c}=0.203$ and $0.263 \mathrm{~m}, A_{c}=0.15 \mathrm{~m}, G_{c}=3 D_{50}$, and $\cot \alpha=1.5$. The armor layer had $D_{50}=0.0382 \mathrm{~m}$ and $n=0.41$, where $D_{50}$ is the nominal diameter, and $n$ is the porosity of the armor layer (see Figure 2). The filter layer had $D_{50}=0.017 \mathrm{~m}$ and the core had $D_{50}=0.007 \mathrm{~m}$. Two crown wall heights were tested: $C_{h}=0.20$ and $0.26 \mathrm{~m}$. Figure 2 shows the cross-section of the physical model with the water level $h=0.55 \mathrm{~m}$.

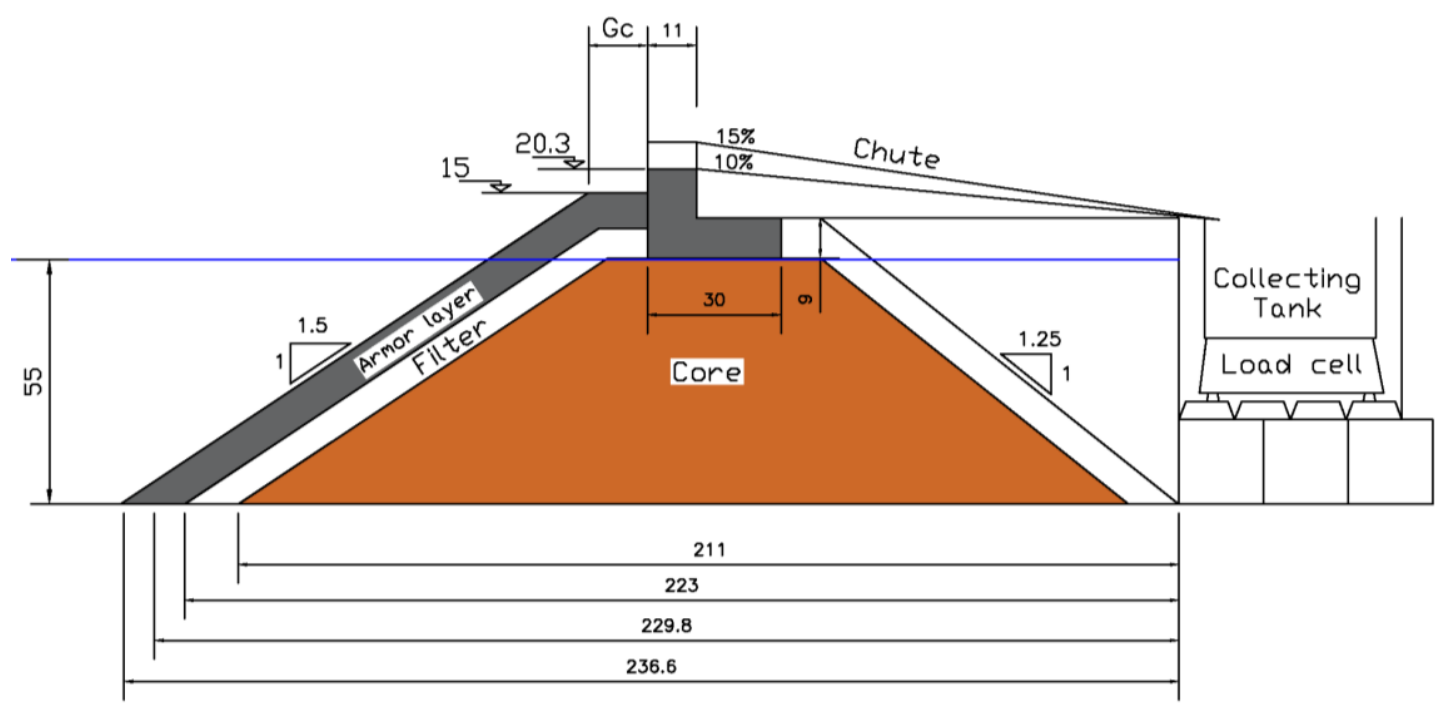

Figure 2. Two-layer Cubipod armored mound breakwater tested by Smolka et al. [12]. Dimensions presented in $\mathrm{cm}$.

Wave conditions, wave overtopping, armor damage, and crown wall stability were analyzed as by Molines [5] and Smolka et al. [12]. Wave forces were measured using seven Drück PDCR 1830 pressure sensors (three on the base and four on the vertical wall). The wave gauges and pressure sensors sampled at $20 \mathrm{~Hz}$. Wave loads on the crown wall were calculated by assuming that each point of the crown wall takes the pressure value of the closest pressure gauge. Figure 3 illustrates the position of the pressure sensors. The result was a wave force calculation based on a rectangular integration of the wave pressures. Pressure sensors placed in dry positions showed noise in some cases, which was eliminated using running average techniques, as seen in Molines [5].

Figure 4 shows the cross-section of the wave flume. The locations of the wave gauges required to apply the method of Mansard and Funke [13] to separate incident and reflected waves are identified as G1 to G8.

The physical model was tested with regular and irregular waves, increasing the incident wave height with an almost constant Iribarren number of $I r_{m}=\tan \alpha /\left(H_{m 0} / L_{m}\right)^{0.5} \approx 4.0$ and $5.0\left(L_{m}\right.$ is the local mean wavelength at the toe). Tests were conducted until massive overtopping occurred or until the initiation of destruction criteria (where the filter layer is visible) were obtained. Irregular wave series were created with 1000 waves and the JONSWAP spectrum with a peak enhancement factor of 3.3. Physical tests were conducted without a reflection absorption system at the wave paddle.

In this study, the numerical model was calibrated in Section 4 using one regular test and seven irregular tests; the characteristics are summarized in Table 1. 


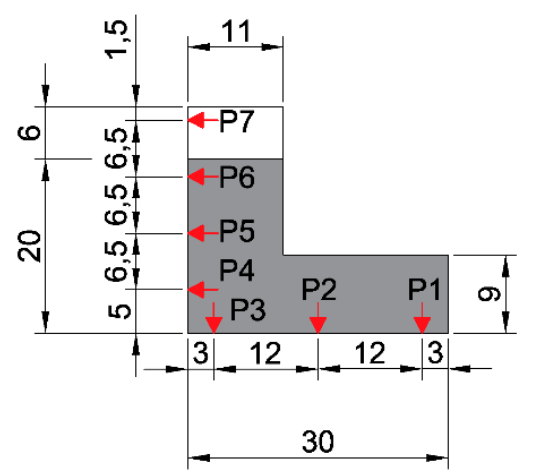

Figure 3. Locations of the pressure sensors in the physical model. Dimensions presented in $\mathrm{cm}$.

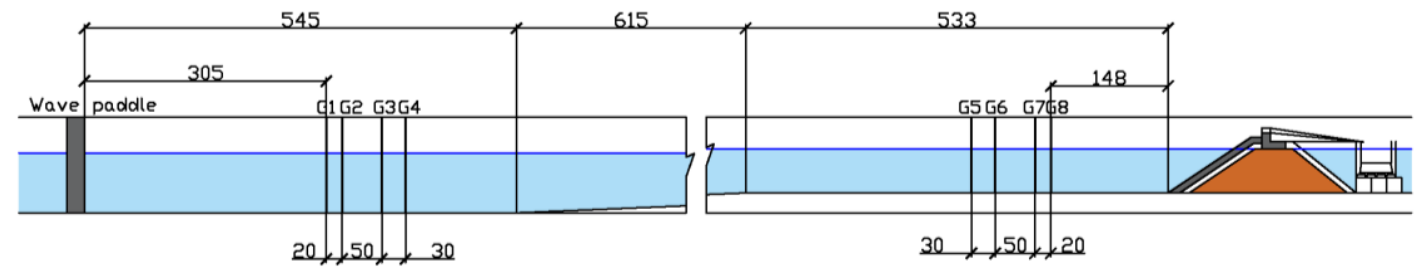

Figure 4. Longitudinal cross-section of the wave flume of the Laboratory of Ports and Coasts at the Universitat Politècnica de València (LPC-UPV). Dimensions presented in $\mathrm{cm}$.

Table 1. Wave characteristics of the physical tests used in this study.

\begin{tabular}{cccc}
\hline $\boldsymbol{I}_{\boldsymbol{m}}$ & $\boldsymbol{H}_{\boldsymbol{m} \boldsymbol{0}}(\mathbf{m})$ & $\boldsymbol{T}_{\boldsymbol{p}}(\mathbf{s})$ & Wave Type \\
\hline 4 & 0.097 & 1.49 & Irregular \\
\hline 4 & 0.113 & 1.70 & Irregular \\
\hline 4 & 0.132 & 1.83 & Irregular \\
\hline 4 & 0.139 & 1.99 & Irregular \\
\hline 5 & 0.099 & 2.22 & Irregular \\
\hline 5 & 0.117 & 2.55 & Irregular \\
\hline 5 & 0.137 & 3.00 & Irregular \\
\hline $\boldsymbol{I} \boldsymbol{r}_{\boldsymbol{m}}$ & $\boldsymbol{H}(\mathbf{m})$ & $\boldsymbol{T}(\mathbf{s})$ & Wave Type \\
\hline 5 & 0.203 & 2.62 & Regular \\
\hline
\end{tabular}

\subsection{Numerical Model}

As discussed previously, the numerical results presented herein were obtained from the model described and validated by Molines et al. [1]. This model, implemented in the open-source platform OpenFOAM ${ }^{\circledR}$, uses the finite volume method (FVM), to provide a discrete solution to the Navier-Stokes equations for incompressible flow:

$$
\begin{gathered}
\nabla \bar{u}=0 \\
\frac{\partial}{\partial \mathrm{t}}(\rho \overline{\mathrm{u}})+\nabla \cdot\left(\frac{1}{\mathrm{n}} \rho \overline{\mathrm{u}} \times \overline{\mathrm{u}}\right)=-\mathrm{n} \nabla \mathrm{p}+\nabla(\mu \nabla \cdot \overline{\mathrm{u}})+\mathrm{n} \rho \overline{\mathrm{f}_{\mathrm{b}}}-\mathrm{I},
\end{gathered}
$$

where $u$ is the fluid velocity, $p$ is the fluid pressure, $\rho$ is the fluid density, $v$ is the kinematic viscosity, and $f_{b}$ represents the body forces, in this case, gravity, and surface tension. ' $I$ ' is the hydraulic gradient according to the Darcy-Forchheimer equation, which is employed to account for energy loss:

$$
\mathrm{I}=A \overline{\mathrm{u}}+\mathrm{B} \overline{\mathrm{u}}|\overline{\mathrm{u}}|+\mathrm{c} \frac{\partial}{\partial \mathrm{t}}(\rho \overline{\mathrm{u}}),
$$


The equations used to estimate the terms $A$ and $B$ may vary slightly, according to the source. In this case, the expression used by van Gent [14] was employed:

$$
\begin{gathered}
A=\alpha \frac{(1-n)^{3}}{n^{2}} \frac{\mu}{D_{50^{2}}} \\
B=\beta\left(1+\frac{7.5}{K C}\right) \frac{1-n}{n^{2}} \frac{\rho}{D_{50}^{2}},
\end{gathered}
$$

where $n$ is the porosity, $D_{50}=\left(M_{50} / \rho_{r}\right)^{1 / 3}$ is the nominal diameter; $M_{50}$ represents the median mass rock elements; $\rho_{r}$ is the mass density of the rock elements; $K C$ is the Keulegan-Carpenter number used to consider the transient nature of flows; and $\alpha, \beta$, and $C$ are empirical parameters. In this study, the parameters $\alpha=200, \beta=1.1, C=0.34, n=0.40, D_{50 \text { Core }}=0.007 \mathrm{~m}, D_{50 \text { Filter }}=0.017 \mathrm{~m}$, and $D_{50 \text { Armor }}=$ $0.038 \mathrm{~m}$ proposed by Molines et al. [1] are used.

The flow model equations were approximated with the PIMPLE algorithm, which combines the PISO and SIMPLE algorithms detailed by Issa [15] and Patankar [16], respectively. These algorithms were implemented in OpenFOAM ${ }^{\circledR}$ as 'interFoam' for transient isothermal incompressible flows comprised of immiscible phases.

The flow under study clearly demands the use of a turbulence model. Nevertheless, authors such as Jacobsen et al. [17] have concluded that a sufficiently accurate estimation of the bulk hydrodynamic variables can be obtained without a turbulence model. In this study, the same approach was adopted, which assumed that all significant energy dissipation processes occur within the porous media (represented by $\alpha$ and $\beta$, as described in Jensen et al. [18]). This hypothesis was verified by Molines et al. [1].

The interface between water and air was identified using the partial volume of fluid (VOF) method proposed by Hirt and Nichols [19] and was implemented in OpenFOAM ${ }^{\circledR}$ with the multidimensional limiter for an explicit solution (MULES), to ensure boundedness and consistency of the fluid fraction (F) field. This variable is the core of the VOF approach and takes values ranging from 0 to 1 . A value of 0 corresponds to a cell filled with air, whereas a value of 1 represents a cell filled with water. The fluid fraction is employed to determine the fluid interface position and to weight the fluid density and viscosity of each mesh cell, and its transport throughout the domain is modeled by an additional convective transport equation:

$$
n \frac{\partial F}{\partial t}+\nabla \cdot(\bar{u} \mathrm{~F})=0
$$

where $u$ is the velocity, and $t$ is the time. Effects such as numerical diffusion mean that cells near the fluid interface take values between 1 and 0 . In order to define a neat interface, the following term is added to Equation (6): $\nabla \bar{u}_{c} \mathrm{~F}(1-\mathrm{F})$, where $u_{c}$ is an artificial compression velocity perpendicular to the fluid interface (see Berberovic et al. [20]).

In this study, a 2D numerical model was used. Jacobsen et al. [21] suggested that flow characteristics in the third coordinate do not appear to be important in porous areas. The only noticeable drawback of 2D models is that air pockets trapped by breaking waves need to form a channel to escape from the water body, which is completely unphysical. This phenomenon was discussed by Jacobsen et al. [17] and must be carefully addressed, as it may lead to a systematic overestimation of the pressures on solid structures.

IHFoam was used to generate the boundary conditions associated with the wave characteristics described in Table 1, along with the active wave absorption method and the porous media, as seen in Higuera et al. [22-25]. A no-slip boundary condition was used to characterize the solid contours, and the upper boundary condition was left open to the atmosphere, thus allowing the free exchange of air with the exterior. A static wavemaker boundary condition was used at the wave paddle.

A 2D structured mesh with rectangular cells was used to discretize the domain, as shown in Figure 5. The mesh was refined up to $1 / 32$ of the mesh cell size in the freestream region $(\Delta x)$. 
A progressive refinement of ratio 4 was also adopted in the x-direction upstream of the breakwater, following the criteria reported by Higuera et al. [22]. Mesh convergence was evaluated using the Richardson extrapolation method to quantify the independence of the results, which showed that convergence was attained with a mesh size of $\Delta x=2 \mathrm{~cm}$ (see Molines et al. [1]).


Figure 5. Mesh detail of the OpenFOAM ${ }^{\circledR}$ model (Source: Molines et al. [1]).

The numerical model simplifications discussed above have led to acceptable results in assessing the performance of coastal structures in the past. This has been corroborated in Molines et al. [1], previous works on coastal structures by Higuera et al. [22] and Castellino et al. [11], and even cases with complex air-water relations, by Bayón et al. [26-28].

Table 2 reports the geometric properties of the crown wall and parapets (see Figure 1b). The same case of wave attack was analyzed by generating irregular wave series following the setup of the experimental model, with the JONSWAP spectrum and peak enhancement factor of 3.3. However, the number of waves was reduced from 1000 to 500 to save computational time.

The same $H_{m 0}$ and $T_{p}$ tested by Smolka et al. [12], and given in Table 1, were tested in the OpenFOAM ${ }^{\circledR}$ model, but with different time series because we used a different seed. This study was conducted using 63 OpenFOAM ${ }^{\circledR}$ tests with irregular waves and one OpenFOAM ${ }^{\circledR}$ test with regular waves. All simulations were run in the RIGEL Computational Cluster of the Universitat Politècnica de València. As reported by Molines et al. [1], the simulation times were, on average, 200 seconds of CPU per second of the simulation.

Wave heights and wave pressures were measured in the numerical model at the same positions as the level and pressure sensors placed in the LPC-UPV wave flume, respectively. All the measurements sampled at $20 \mathrm{~Hz}$. Figure 6 illustrates the position of the pressure sensors on a crown wall with a parapet. Wave loads on the crown wall were evaluated, considering that each point of the crown wall 
takes the pressure value of the nearest pressure sensor. The result is a wave force calculation based on a rectangular integration of the wave pressures.

Table 2. Characteristic structures analyzed in the OpenFOAM ${ }^{\circledR}$ model.

\begin{tabular}{ccccccc}
\hline Structure \# & $\boldsymbol{R}_{\boldsymbol{c}}=C_{\boldsymbol{h}}(\mathrm{m})$ & $C_{b}(\mathrm{~m})$ & Parapet & $w_{p}(\mathrm{~m})$ & $h_{p}(\mathrm{~m})$ & $\varepsilon_{p}\left({ }^{\circ}\right)$ \\
\hline A0 & 0.20 & 0.30 & No & - & - & - \\
\hline A1 & 0.20 & 0.30 & Yes & 0.025 & 0.025 & 30 \\
\hline B0 & 0.26 & 0.30 & No & - & - & - \\
\hline B1 & 0.26 & 0.30 & Yes & 0.025 & 0.025 & 30 \\
\hline B2 & 0.26 & 0.30 & Yes & 0.025 & 0.050 & 30 \\
\hline B3 & 0.26 & 0.30 & Yes & 0.050 & 0.025 & 30 \\
\hline B4 & 0.26 & 0.30 & Yes & 0.025 & 0.025 & 60 \\
\hline B5 & 0.26 & 0.30 & Yes & 0.025 & 0.050 & 60 \\
\hline B6 & 0.26 & 0.30 & Yes & 0.050 & 0.025 & 60 \\
\hline
\end{tabular}

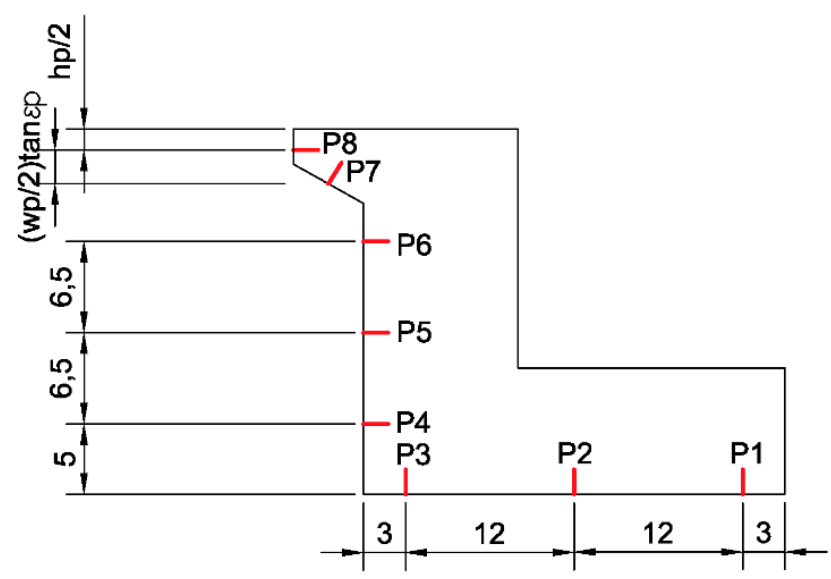

Figure 6. Pressure sensors placed in the crown wall with a parapet. Dimensions are presented in centimeters.

\section{Validation of the OpenFOAM ${ }^{\circledR}$ Model}

In this study, the goodness of fit was measured using the relative mean-squared error given by Equation (7):

$$
r M S E=\frac{M S E}{\operatorname{Var}}=\frac{1}{N} \sum_{i=1}^{N} \frac{\left(o_{i}-e_{i}\right)^{2}}{\operatorname{Var}\left(o_{i}\right)}
$$

where MSE is the mean-squared error, Var is the variance of the measurements, $N$ is the number of data, $o_{i}$ is the measured value, and $e_{i}$ is the predicted value. $0 \% \leq r M S E \leq 100 \%$ is approximately the percentage of variance not described by the estimator.

Molines et al. [1] validated the OpenFOAM ${ }^{\circledR}$ model with physical tests without parapets, denoted as structure \#A0 in this study. The validation of Molines et al. [1] satisfactorily compared the wave heights, wave periods, reflection coefficient, and dimensionless mean wave overtopping discharge. Sections 4.1 and 4.2 provide the validation with regular and irregular waves regarding the wave forces, respectively. The validated numerical model allowed an analysis of the influence of the parapet geometry on the wave forces on crown walls, as presented in Section 5. 


\subsection{Regular Test}

The performance of the numerical model in the time domain was conducted with one regular test with $H=0.203 \mathrm{~m}$ and $T=2.62 \mathrm{~s}$, using structure \#A0 without a parapet. Figure 7 illustrates the up-lift pressures at P1, P2, and P3 and the horizontal pressures at P4, P5, and P6. Figure 7 shows good agreement between the wave pressures given in the numerical test and those measured in the physical test. Wave pressures on a crown wall exhibit large variability; horizontal pressures measured in the laboratory under regular waves provided a mean value, $\bar{p}$, and a standard deviation, std, of $\bar{p}=13.4 \mathrm{~cm}$ and $s t d=2.0 \mathrm{~cm}$ at $\mathrm{P} 4$, and $\bar{p}=10.2 \mathrm{~cm}$ and $s t d=4.2 \mathrm{~cm}$ at P6, respectively. Therefore, the numerical model could reasonably represent the horizontal pressures. Differences were observed in the up-lift pressures due to the small difference in foundation level caused by cell size restrictions $\left(F_{\mathcal{C}_{-} \text {OpenFOAM }}=0 \mathrm{~m}\right.$ and $\left.F_{c_{-} \text {laboratory }}=0.033 \mathrm{~m}\right)$. Figure 8 shows the pressure distribution of the regular test in $\mathrm{t}=25.15 \mathrm{~s}$, corresponding to one of the highest wave impacts.

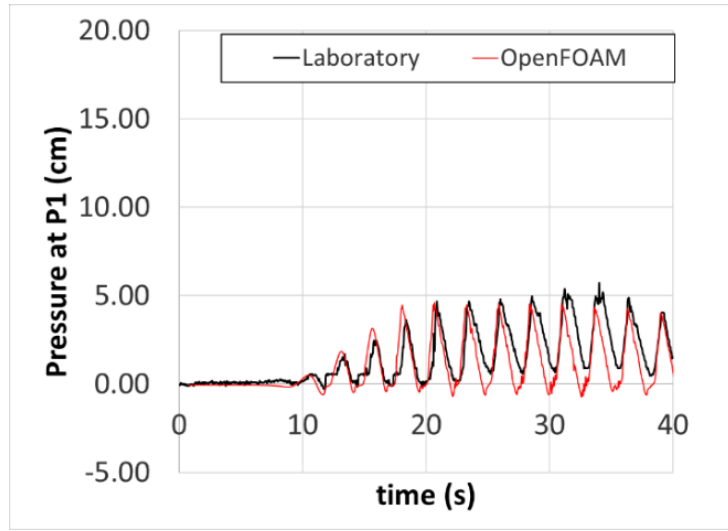

(a)

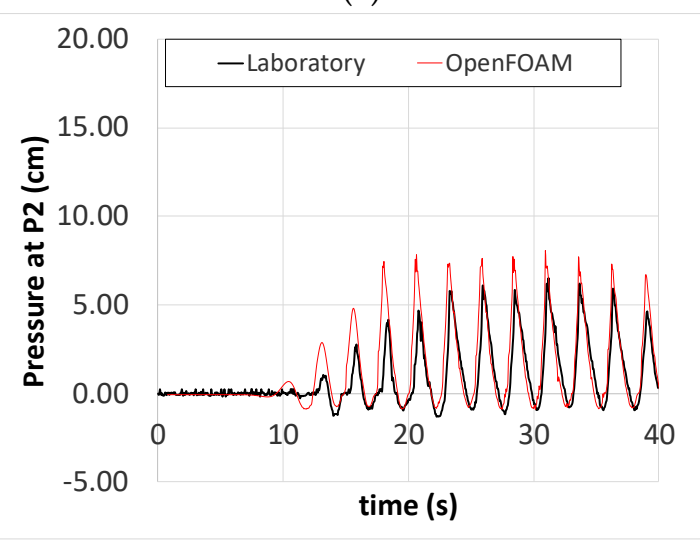

(c)

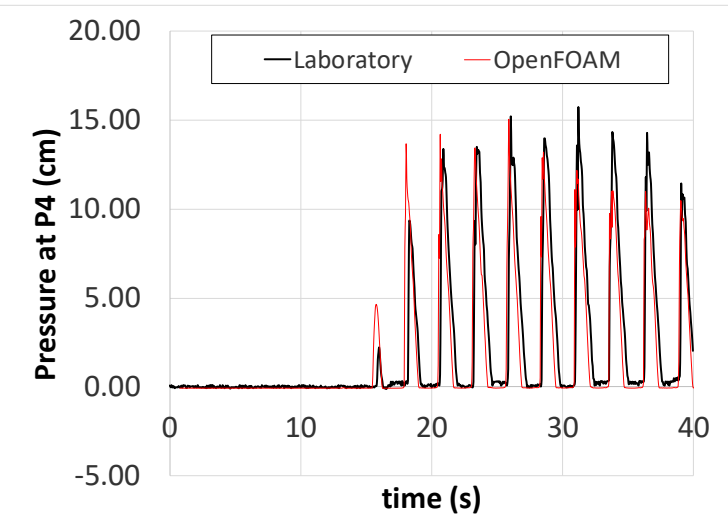

(b)

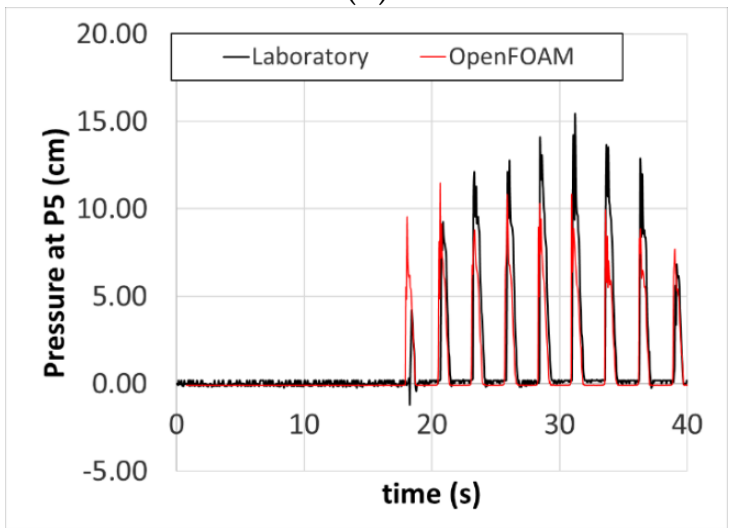

(d)

Figure 7. Cont. 


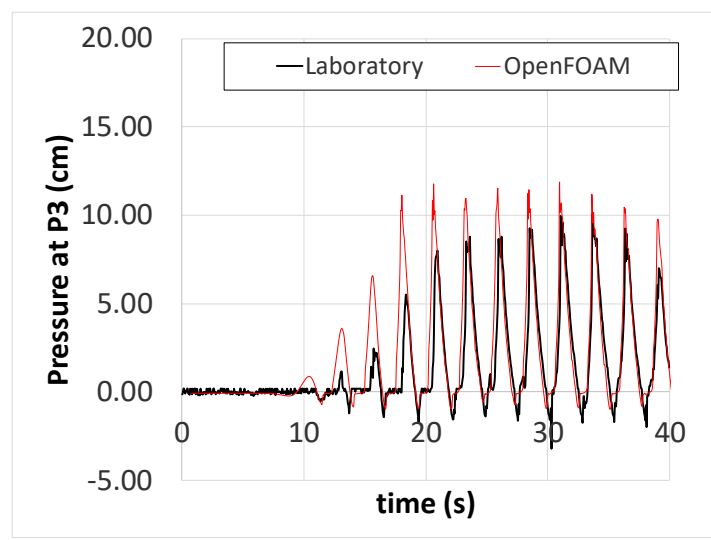

(e)



(f)

Figure 7. Validation of the OpenFOAM ${ }^{\circledR}$ model using a physical test with regular waves of $H=0.203 \mathrm{~m}$ and $T=2.62 \mathrm{~s}:(\mathbf{a}, \mathbf{c}, \mathbf{e})$ display up-lift pressures, and $(\mathbf{b}, \mathbf{d}, \mathbf{f})$ display horizontal pressures.

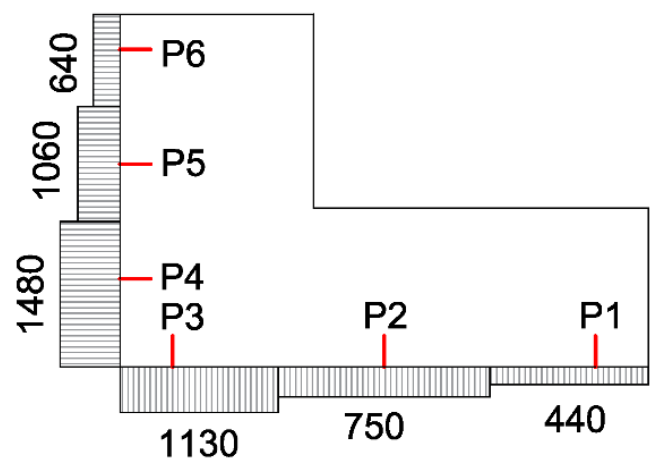

Figure 8. Peak pressure distribution of the physical test with regular waves of $H=0.203 \mathrm{~m}$ and $T=2.62 \mathrm{~s}$ in $\mathrm{t}=25.15 \mathrm{~s}$. Units presented in Pascals.

\subsection{Irregular Tests}

The performance of the OpenFOAM ${ }^{\circledR}$ model with irregular waves was investigated with the irregular tests given in Table 1 . Figure 9 compares the results of the numerical and physical tests of structure \#A0 without a parapet; $F h_{\max }$ is the maximum horizontal wave force, $F v F h_{\max }$ is the up-lift force generated by the wave that caused $F h_{\max }$, and $M h F h_{\max }$ is the overturning moment due to horizontal forces generated by the wave that caused $F h_{\max }$. The estimations of $F h_{\max }, F v F h_{\max }$, and $M h F h_{\text {max }}$ provided $r M S E=41.7 \%,>100 \%$, and $12.8 \%$, respectively.

Romano et al. [29] noticed that when $R_{c} / H_{m 0}<1.2$, the wave overtopping measurements showed a variability of $20 \%$; when $R_{c} / H_{m 0}>1.4$, the variability was one order of magnitude. Furthermore, wave overtopping is highly influenced by variations in $H_{m 0}$, which is predicted in OpenFOAM ${ }^{\circledR}$ with $r M S E=2.4 \%$ (see Molines et al. [1]). The OpenFOAM ${ }^{\circledR}$ predictions of $F h_{\max }$ and $M h F h_{\max }$, provided in Figure 9a,c, are acceptable according to (1) the sources of variability in the wave forces described in Section 4.1, (2) the variability in wave overtopping described by Romano et al. [29], and (3) the relevance of wave overtopping for estimating wave forces on crown walls (Molines et al. [6]).

The overestimation of up-lift wave forces given in Figure $9 \mathrm{~b}$ can be explained since the foundation level of the crown wall in the numerical model was set to $0 \mathrm{~m}$ due to cell size restrictions, while in the laboratory model, the foundation level was set to $0.033 \mathrm{~m}$. Up-lift forces are produced by the wave flow through the porous media and are thus highly affected by the foundation level. 


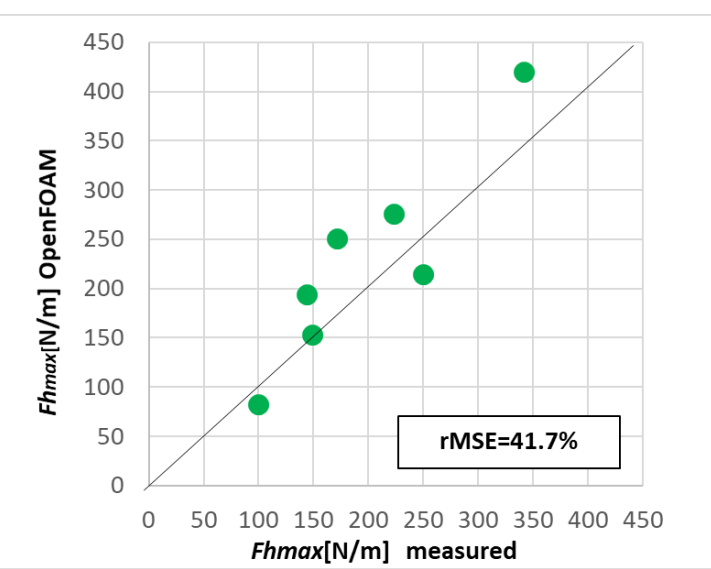

(a)

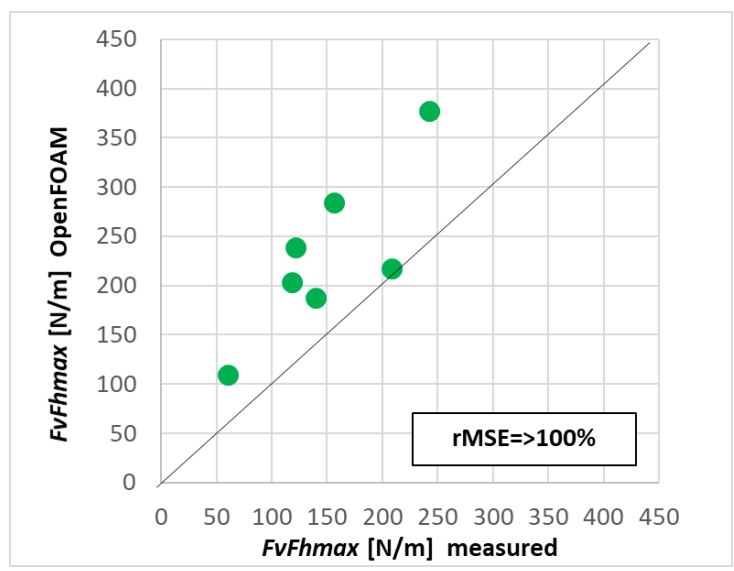

(b)



(c)

Figure 9. Validation with irregular tests of the OpenFOAM ${ }^{\circledR}:$ (a) $F h_{\max }$, (b) $F v F h_{\max }$, and (c) $M h F h_{\max }$.

\section{Influence of a Parapet on Wave Forces on Crown Walls}

In this section, wave forces on the crown walls of mound breakwaters with parapets are compared to those without parapets (see Figure 10). Structure \#A1 was compared to structure \#A0, and structures \#B1 to \#B6 were compared to structure \#B0. In this study, the wave forces were made dimensionless as $F h=F h_{\max } /\left(0.5 \rho g C_{h}^{2}\right), F v F=F v F h_{\max } /\left(0.25 \rho g C_{h} C_{b}\right)$, and $M h F=M h F h_{\max } /\left(\rho g C_{h}{ }^{3}\right) . F v F h_{\text {max }}$ and $M h F h_{\text {max }}$ were generated by the same wave as $F h_{\max }$. These dimensionless wave forces and overturning moments were used by Molines [5].

Figure 11a-c, illustrates the comparison of $F h_{0}$ and $F h_{p}, F v F_{0}$ and $F v F_{p}$, and $M h F_{0}$ and $M h F_{p}$, respectively, where the subscript ' 0 ' indicates the structures without parapets (\#A0 and \#B0), and the subscript ' $\mathrm{p}$ ' indicates the structures with parapets (\#A1 and \#B1 to \#B6). The blue dashed line in Figure 11a,c shows the linear regression comparing structures \#A0 and \#A1.

Figure 12 illustrates the relationship between $F h, F v F$, and $M h F$ with $R_{c} / H_{m 0}$. The black dashed line in Figure 12a,c shows the linear regression comparing $F h$ and $M h F$ with $R_{c} / H_{m 0}$ of structure \#A0, respectively. The solid black line in Figure 12a,c shows the linear regression comparing $F h$ and $M h F$ with $R_{c} / H_{m 0}$ of structure \#A1, respectively. In all cases, the higher the $R_{c} / H_{m 0}$, the lower the dimensionless wave forces.

Figures 11 and 12 show that models \#B0 to \#B6 with higher crown walls with $1.9<R_{c} / H_{m 0}<2.6$ exhibit a larger dispersion of the measurements than models \#A0 and \#A1, with shorter crown walls with $1.4<R_{c} / H_{m 0}<2.0$. Although there is a large amount of scatter in the data, it seems that $F h$ and $M h F$ show a tendency to increase when there is a parapet, while $F v F$ provides similar values, regardless of the existence of a parapet. Figures 11 and 12 show that $F h$ and $M h F$ increase with a factor around 2 
when there is a parapet in structures \#A0 and \#A1 (similar to the result given by Pearson et al. [10] for vertical breakwaters).

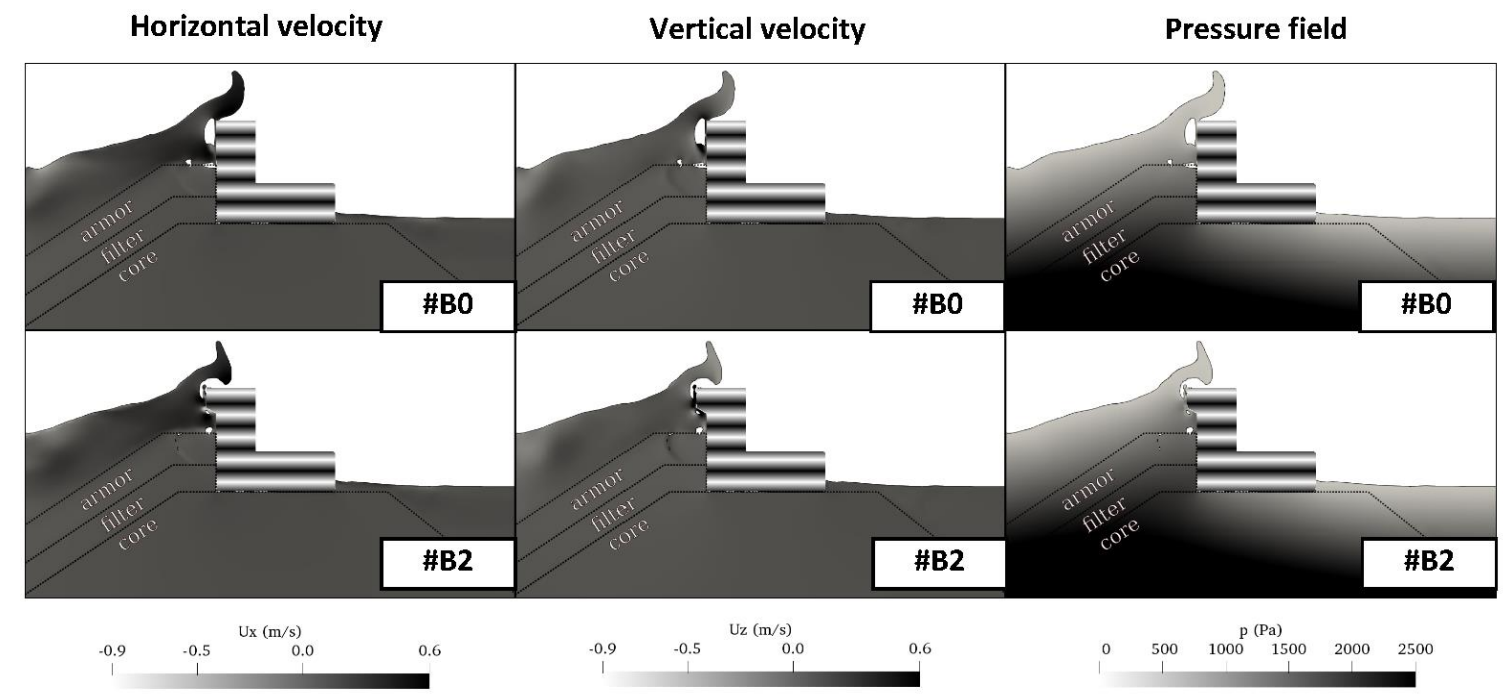

Figure 10. Comparison of pressure field and velocity components. Simulation of $180 \mathrm{~s}$ of testing with $H_{m 0 i}=0.14 \mathrm{~m}$ and $T_{p}=3 \mathrm{~s}$, and models \#B0 and \#B2.

Figure 13 illustrates the influence of $\varepsilon_{p}$ and $w_{p} / h_{p}$ on $F h_{p} / F h_{0}$ (similar figures were obtained for $F v F_{p} / F v F_{0}$ and $\left.M h F_{p} / M h F_{0}\right)$. The dotted lines correspond to the median values. The variability of the wave forces is so high that no significant influence of the parapet geometry can be derived.



(a)

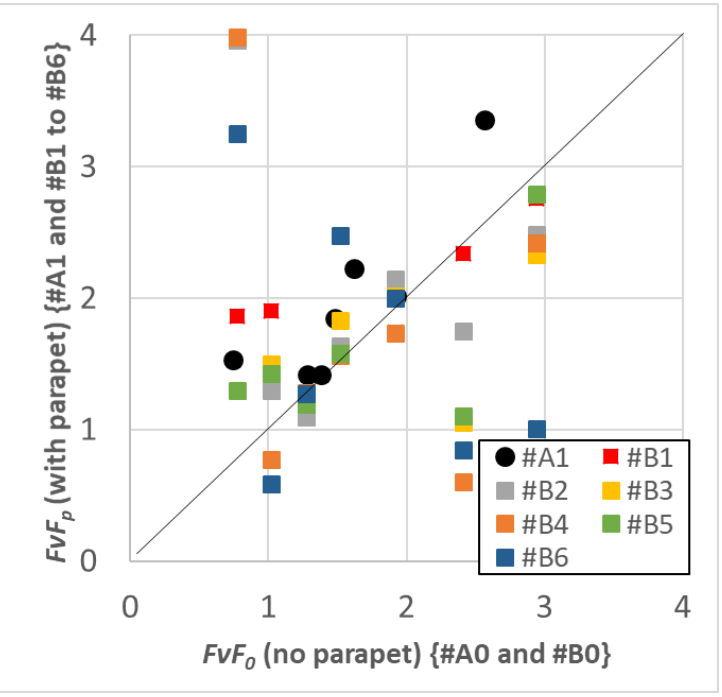

(b)

Figure 11. Cont. 


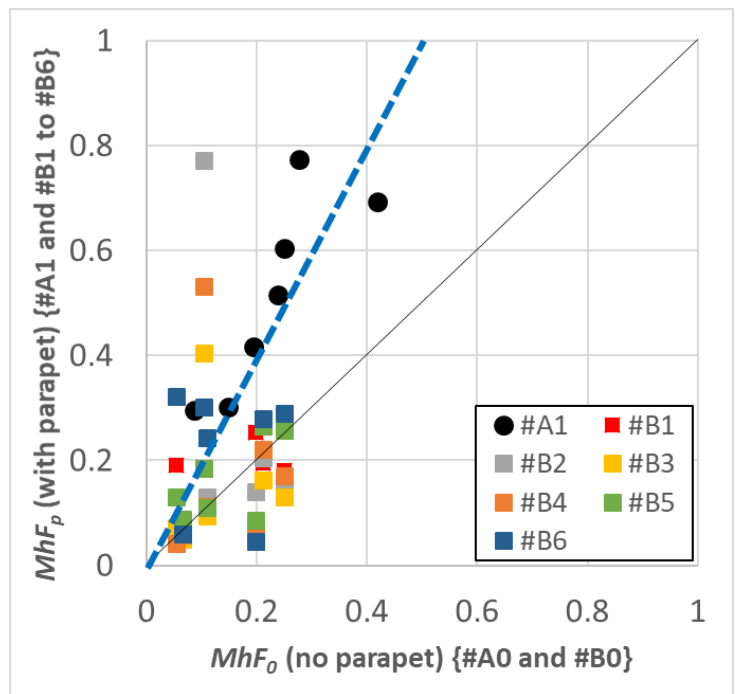

(c)

Figure 11. Comparison of (a) $F h_{0}$ and $F h_{p}$, (b) $F v F_{0}$ and $F v F_{p}$, and (c) $M h F_{0}$ and $M h F_{p}$.

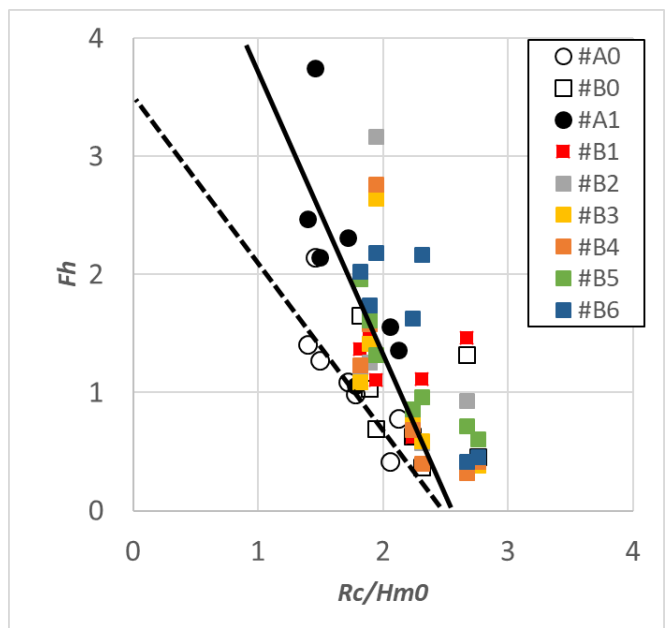

(a)

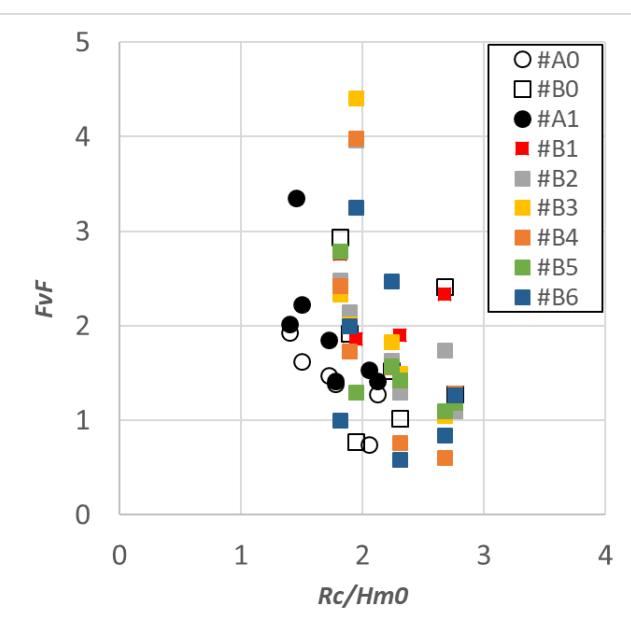

(b)

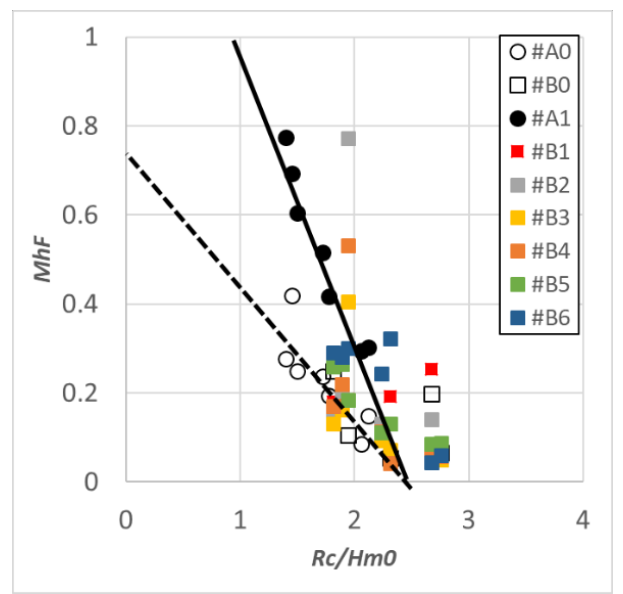

(c)

Figure 12. Comparison of (a) $F h$, (b) FvF, and (c) $M h F$ with $R_{c} / H_{m 0}$. 


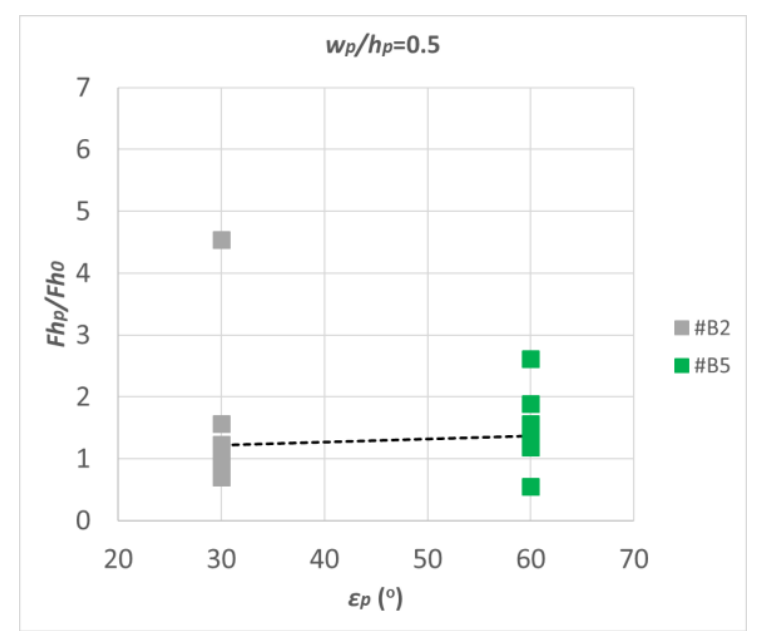

(a)

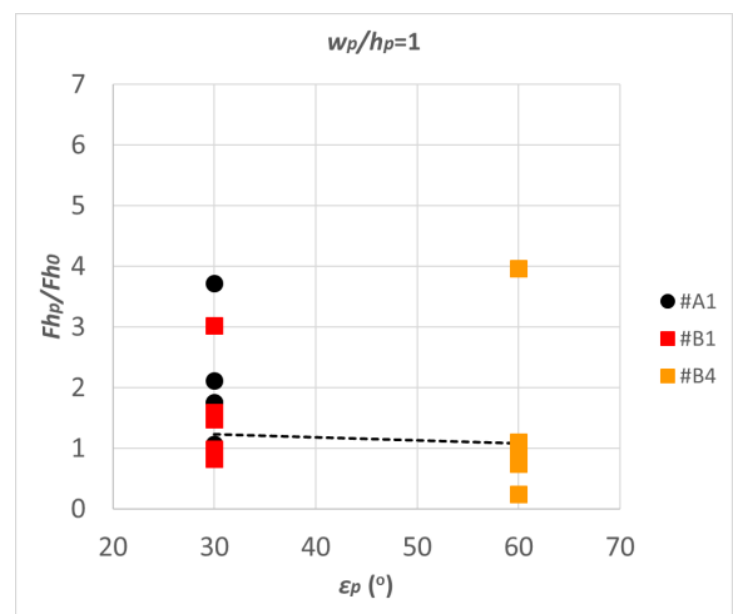

(b)



(c)

Figure 13. Influence of the parapet angle on $F h_{p} / F h_{0}$ for $(\mathbf{a}) w_{p} / h_{p}=0.5,(\mathbf{b}) w_{p} / h_{p}=1$, and (c) $w_{p} / h_{p}=2$.

\section{Conclusions}

In this study, numerical simulations using the open-source platform OpenFOAM ${ }^{\circledR}$ were conducted to analyze the influence of the parapet characteristics on the dimensionless wave forces on crown walls of mound breakwaters. The numerical model was validated in Molines et al. [1] using the physical tests with a plain wall conducted by Smolka et al. [12]; the OpenFOAM ${ }^{\circledR}$ model was validated in the time domain with one regular test, while statistical validation was conducted with seven irregular tests. The estimations provided by the numerical model of the dimensionless horizontal force $(F h)$ and dimensionless overturning moment due to horizontal forces $(M h F)$ for irregular waves had percentages of non-explained variance given by $r M S E=41.7 \%$ and $12.8 \%$, respectively.

The output of the numerical model was used to characterize the influence of the parapet characteristics on the dimensionless wave forces on crown walls. The existence of a parapet increased the $F h$ and $M h F$ by a factor of around 2. FvF provides similar values, regardless of the existence of a parapet. Cross-sections with higher crown walls with $1.9<R_{c} / H_{m 0}<2.6$ exhibit larger dispersion of the force measurements than cross-sections with shorter crown walls with $1.4<R_{c} / H_{m 0}<2.0$.

Author Contributions: Conceptualization, J.M. and J.R.M.; methodology, J.M.; software, J.M. and A.B.; validation, J.M., and M.E.G.-M.; formal analysis, J.M.; investigation, J.M.; resources, J.M., M.E.G.-M. and J.R.M.; data curation, J.M.; writing—original draft preparation, J.M.; writing—review and editing, J.M., A.B., M.E.G.-M. and J.R.M.; visualization, J.M., A.B. and M.E.G.-M.; supervision, J.M.; project administration, J.M.; funding acquisition, J.M., 
M.E.G.-M. and J.R.M. All authors have read and agreed to the published version of the manuscript. Please turn to the CRediT taxonomy for the term explanation. Authorship must be limited to those who have contributed substantially to the work reported.

Funding: This research was funded by (1) Universitat Politècnica de València (Grant SP20180111, Primeros Proyectos de Investigación (PAID-06-18), Vicerrectorado de Investigación, Innovación y Transferencia de la Universitat Politècnica de València) and (2) Spanish Ministerio de Ciencia, Innovación y Universidades (Grant RTI2018-101073-B-I00).

Acknowledgments: The authors are grateful for financial support from the European FEDER and Spanish Ministerio de Ciencia, Innovación y Universidades (Grant RTI2018-101073-B-I00), SATO (OHL Group), and Universitat Politècnica de València (Grant SP20180111, Primeros Proyectos de Investigación (PAID-06-18), Vicerrectorado de Investigación, Innovación y Transferencia de la Universitat Politècnica de València). The authors acknowledge the support provided by the postdoctoral program AEST granted to Jorge Molines by Generalitat Valenciana (Grant AEST/2019/004), and by the postdoctoral program APOSTD granted to Arnau Bayón by Generalitat Valenciana (Grant APOSTD/2019/100). The authors thank Moisés Belda for his collaboration in preparing, running, and analyzing the tests.

Conflicts of Interest: The authors declare no conflict of interest.

\section{References}

1. Molines, J.; Bayon, A.; Gómez-Martín, M.E.; Medina, J.R. Influence of parapets on wave overtopping on mound breakwaters with crown walls. Sustainability 2019, 11, 7109. [CrossRef]

2. Martinelli, L.; Ruol, P.; Volpato, M.; Favaretto, C.; Castellino, M.; De Girolamo, P.; Franco, L.; Romano, A.; Sammarco, P. Experimental investigation on non-breaking wave forces and overtopping at the recurved parapets of vertical breakwaters. Coast. Eng. 2018, 141, 52-67. [CrossRef]

3. Pedersen, J. Wave Forces and Overtopping on Crown Walls of Rubble Mound Breakwaters; Series Paper 12; Hydraulic and Coastal Engineering Laboratory, Department of Civil Engineering, Aalborg University: Aalborg, Denmark, 1996.

4. Norgaard, J.Q.H.; Lykke-Andersen, T.; Burcharth, H.F. Wave loads on rubble mound breakwater crown walls in deep and shallow-water wave conditions. Coast. Eng. 2013, 80, 137-147. [CrossRef]

5. Molines, J. Wave Overtopping and Crown Wall Stability of Cube and Cubipod-Armored Mound Breakwaters. Ph.D. Thesis, Universitat Politecnica de Valencia, Valencia, Spain, 2016.

6. Molines, J.; Herrera, M.P.; Medina, J.R. Estimations of wave forces on crown walls based on wave overtopping rates. Coast. Eng. 2018, 132, 50-62. [CrossRef]

7. Van Gent, M.R.A.; van der Werf, I.M. Influence of oblique wave attack on wave overtopping and forces on rubble mound breakwater crest walls. Coast. Eng. 2019, 151, 78-96. [CrossRef]

8. Kortenhaus, A.; Pearson, J.; Bruce, T.; Allsop, N.W.H.; van der Meer, J.W. Influence of Parapets and Recurves on Wave Overtopping and Wave Loading of Complex Vertical Walls. In Coastal Structures; ASCE: Reston, VA, USA, 2003; pp. 369-381.

9. Kortenhaus, A.; Haupt, R.; Oumeraci, H. Designs Aspects of Vertical Walls with Steep Foreland Slopes. In Breakwaters, Coastal Structures and Coastlines; ICE: London, UK, 2001; pp. 221-232.

10. Pearson, J.; Bruce, T.; Allsop, N.W.H.; Kortenhaus, A.; van der Meer, J.W. Effectiveness of Recurve Walls in Reducing Wave Overtopping on Seawalls and Breakwaters. In Proceedings of the 29th International Conference on Coastal Engineering, Lisbon, Portugal, 19-24 September 2004; pp. 4404-4416.

11. Castellino, M.; Sammarco, P.; Romano, A.; Martinelli, L.; Ruol, P.; Franco, L.; De Girolamo, P. Large impuplsive forces on recurved parapets under non-breaking waves. A numerical study. Coast. Eng. 2018, 136, 1-15. [CrossRef]

12. Smolka, E.; Zarranz, G.; Medina, J.R. Estudio Experimental del Rebase de un Dique en Talud de Cubípodos. Libro de las X Jornadas Españolas de Costas y Puertos; Universidad de Cantabria-Adif Congresos: Santander, Spain, 2009; pp. 803-809. (In Spanish)

13. Mansard, E.P.D.; Funke, E.R. The Measurement of Incident and Reflected Spectra Using a Least Swuares Method. In Proceedings of the 17th International Conference on Coastal Engineering, Sydney, Australia, 23-28 March 1980; pp. 154-172.

14. Van Gent, M.R.A. Wave Interaction with Permeable Coastal Structures. Ph.D. Thesis, Delft University, Delft, The Netherlands, 1995. 
15. Issa, R.I. Solution of the implicitly discretized fluid flow equations by operator-splitting. J. Comput. Phys. 1985, 62, 40-65. [CrossRef]

16. Patankar, S.V.; Spalding, D.B. A calculation procedure for heat, mass and momentum transfer in three-dimensional parabolic flows. J. Heat Mass Transf. 1972, 15, 1787-1806. [CrossRef]

17. Jacobsen, N.G.; van Gent, M.R.A.; Capel, A.; Borsboom, M. Numerical prediction of integrated wave loads on crest walls on top of rubble mound structures. Coast. Eng. 2018, 142, 110-124. [CrossRef]

18. Jensen, B.; Jacobsen, N.G.; Christensen, E.D. Investigations on the porous media equations and resistance coefficients for coastal structures. Coast. Eng. 2014, 84, 56-72. [CrossRef]

19. Hirt, C.W.; Nichols, B.D. Volume of fluid (VOF) method for the dynamics of free boundaries. J. Comput. Phys. 1981, 39, 201-225. [CrossRef]

20. Berberovic, E.; van Hinsberg, N.P.; Jakirlic, S.; Roisman, I.V.; Tropea, C. Drop impact onto a liquid layer of finite thickness: Dynamics of the cavity evolution. Phys. Rev. 2009, 79, 036306. [CrossRef] [PubMed]

21. Jacobsen, N.G.; van Gent, M.R.; Wolters, G. Numerical analysis of the interaction of irregular waves with two dimensional permeable coastal structures. Coast. Eng. 2015, 102, 13-29. [CrossRef]

22. Higuera, P.; Lara, J.L.; Losada, I.J. Three-dimensional interaction of waves and porous coastal structures using OpenFOAM. Part II: Applications. Coast. Eng. 2014, 83, 259-270. [CrossRef]

23. Higuera, P.; Lara, J.L.; Losada, I.J. Realistic wave generation and active wave absorption for Navier-Stokes models: Application to OpenFOAM. Coast. Eng. 2013, 71, 102-118. [CrossRef]

24. Higuera, P.; Lara, J.L.; Losada, I.J. Simulating coastal engineering processes with OpenFOAM. Coast. Eng. 2013, 71, 119-134. [CrossRef]

25. Higuera, P.; Lara, J.L.; Losada, I.J. Three-dimensional interaction of waves and porous coastal structures using OpenFOAM. Part I: Formulation and validation. Coast. Eng. 2014, 83, 243-258. [CrossRef]

26. Bayon, A.; Lopez-Jimenez, P.A. Numerical analysis of hydraulic jumps using OpenFOAM. J. Hydroinf. 2015, 17, 662-678. [CrossRef]

27. Bayon, A.; Valero, D.; Garcia-Bartual, R.; Valles-Moran, F.J.; Lopez-Jimenez, P.A. Performance assessment of OpenFOAM and flow-3d in the numerical modeling of a low reynolds number hydraulic jump. Environ. Model. Softw. 2016, 80, 322-335. [CrossRef]

28. Bayon, A.; Toro, J.P.; Bombardelli, F.A.; Matos, J.; López-Jiménez, P.A. Influence of VOF technique, turbulence model and discretization scheme on the numerical simulation of the non-aerated, skimming flow in stepped spillways. J. Hydro Environ. Res. 2018, 19, 137-149. [CrossRef]

29. Romano, A.; Bellotti, G.; Briganti, R.; Franco, L. Uncertainties in the physical modelling of the wave overtopping over a rubble mound breakwater: The role of the seeding number and of the test duration. Coast. Eng. 2015, 103, 15-21. [CrossRef] 